\title{
Hydatid pulmonary cyst: A case report
}

\author{
Baltazar Pech-Alonso ${ }^{1 *}$, Cruzilet Fermín-Hernández¹, Claudia Meixueiro-Calderón ${ }^{1}$, \\ Benito Vargas-Abrego², Irma Flores-Colín ${ }^{2}$ and Raúl J. Cicero-Sabido \\ ${ }^{1}$ Navy Medical Center, Navy Secretariat, SEMAR; ${ }^{2}$ Pulmonology unit "Dr. Alejandro Celis", General Hospital of Mexico "Dr. Eduardo Liceaga”. Mexico \\ City, Mexico
}

\begin{abstract}
Lung Echinococcosis is a parasitic disease caused by tapeworms from Echinococcus spp genus. It is a global distribution disease when people have closed relation with animals like dogs and lambs. Humans are accidental hosts. The liver is the most affected site followed by the lungs. We present one case of a patient who works with lambs and come from an endemic area in our country.
\end{abstract}

Key words: Hydatid cyst. Pulmonary hydatid. Echinococcosis.

\section{Introduction}

Echinococcosis is a zoonosis caused by adult larvae (metacestodes) of Echinococcus granulosus. This belongs to the genus Echinococcus and the family Taeniidae. There are several species of Echinococcus: E. granulosus, Echinococcus multilocularis, Echinococcus oligarthrus, and Echinococcus vogeli and among others ${ }^{1-3}$. E. granulosus (cause of cystic echinococcosis) and E. multilocularis (alveolar or disseminated echinococcosis) are the most clinically relevant species ${ }^{4}$. E. granulosus requires two hosts to complete its life cycle. It inhabits the intestine of the canines, predominantly dogs (definitive host), and other vertebrate species (sheep, cows, goats, horses, and pigs) are called intermediate hosts. Man is an accidental host in the parasite's biological cycle ${ }^{5}$. Morphologically, this hermaphrodite worm has a specialized organ composed of suckers and hooks called scolex in addition to a segmented body called proglottids. The infective form is the embryonic egg present in feces of animals ${ }^{6}$. This pulmonary parasitosis is common in countries of the Middle East, Europe, and the Mediterranean ${ }^{7}$. The age of presentation is variable, with an increase in the second and third decades of life, and it is more prevalent in men ${ }^{8,9}$. In Mexico, an animal study conducted by Vargas et al. demonstrated the presence of $E$. granulosus in the liver $(92.6 \%)$ of pigs, from farms, for human consumption ${ }^{10}$. So far, there is no clinical evidence to determine the exact prevalence of this infection in our country since most of the cases are isolated reports ${ }^{11,12}$. Here, we present a clinical case of a woman from an area of sheep care and consumption in our country.

\section{Clinical case}

A 39-year-old woman in contact with sheep since childhood, she was admitted to the pulmonology service of our hospital due to general weakness, oppressive retrosternal pain of variable intensity with irradiation

\section{Correspondence:}

*Baltazar Pech-Alonso

E-mail: drbaltazarp@gmail.com
Available online: $30-07-2019$
Date of reception: 15-05-2017

Date of acceptance: 31-08-2017

DOI: 10.24875/HGMX.M19000020
Rev Med Hosp Gen Mex. 2019;82(2):112-115

www.hospitalgeneral.mx 0185-1063/@ 2017 Sociedad Médica del Hospital General de Mexico. Published by Permanyer México SA de CV. This is an open access article under the CC BY-NC-ND license (http://creativecommons.org/licenses/by-nc-nd/4.0/). 


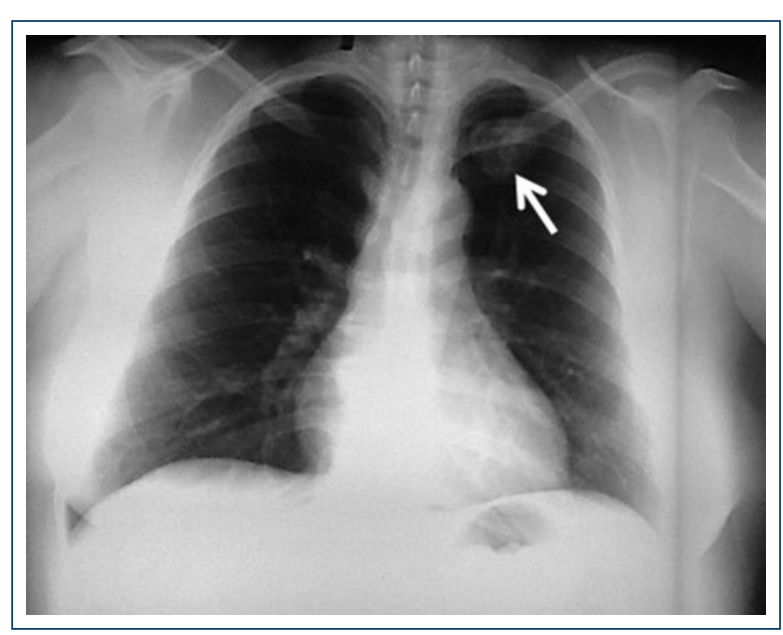

Figure 1. Chest X-ray with round opacity of defined edges in left apex (arrow).

to the left scapular region that improves with the intake of non-specified analgesics, productive cough with hyaline sputum and dyspnea secondary to minimal efforts of 3 months evolution. On plain chest radiography, a round opacity was observed at the left pulmonary apex, approximately $4 \mathrm{~cm}$ in diameter (Fig. 1). The physical examination did not include any pleuropulmonary syndrome; laboratory studies showed no peripheral eosinophilia and spirometry was normal. On testing with computed axial tomography (Computed tomography $[\mathrm{CT}]$ ), hyperdense round image with well-defined edges of $3.7 \mathrm{~cm} \times 3.4 \mathrm{~cm}$ with air inside (sign of increasing air) and peripheral reinforcement surrounded by healthy lung tissue with the contrast medium (Fig. 2) were observed. Fiberoptic bronchoscopy with white light and no relevant findings was observed. Culture did not develop for fungi, bacteria, and mycobacteria in bronchial lavage of the left upper lobe segments. Suspected diagnosis of pulmonary hydatidosis was due to prolonged exposure to sheep in addition to clinical and imaging data (no serological or molecular studies were performed for this case). The surgical treatment consisted of wedge resection of the left apicoposterior segment without rupture of the wall surrounding the lesion (Fig. 3A). The definitive histopathological report was compatible with hydatid pulmonary cyst (Fig. 3B and C). She had a normal post-operative period, and pleurostomy (anterior and posterior) catheters were removed 7 days after the surgical procedure without complications.

She completed treatment with albendazole $(10 \mathrm{mg} /$ $\mathrm{kg} / \mathrm{day}$ ) for 3 months. The control hepatic ultrasound ruled out the presence of cysts and a chest X-ray

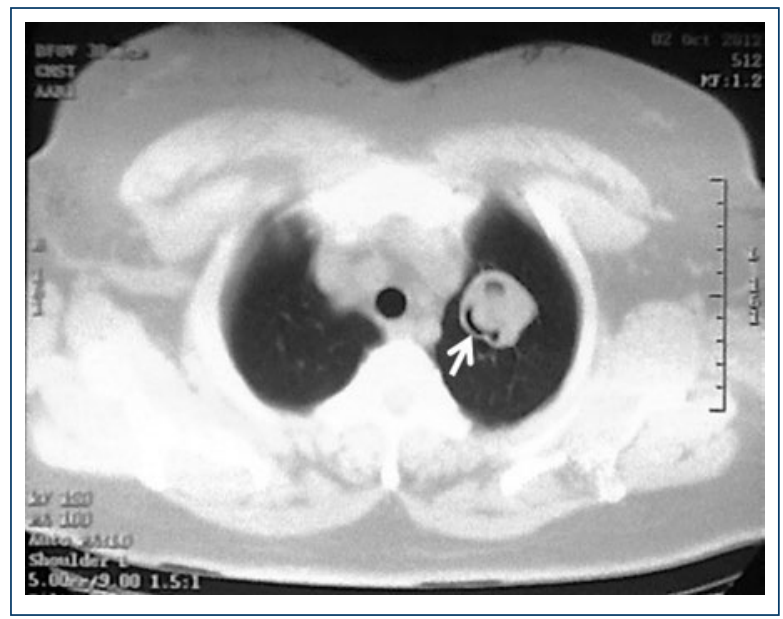

Figure 2. Simple thoracic tomography with a hyperdense round image with air inside (increasing air sign) in left apex (arrow).

1 year after surgery, with bronchiectasis located in a surgical site.

\section{Discussion}

In Mexico, this parasitism is rare and the cases found were associated with close contact with dogs or sheep. The pulmonary hydatid cyst may remain silent for long periods of time, and the symptoms are a consequence of capsular rupture or by direct compression of adjacent structures during its growth. However, more than half of the patients are asymptomatic ${ }^{13}$. The presence of dry cough and chest pain is the main symptoms of presentation. Expectoration of cystic membranes or hydatidosis is a pathognomonic sign, but of rare presentation ${ }^{14}$. According to Jerray et al., in a review of 386 cases of pulmonary hydatidosis, more than half of patients had a productive cough, chest pain, and hemoptysis at the time of diagnosis ${ }^{15}$. For this reason, it is common that some cases are confused with infection by Mycobacterium tuberculosis ${ }^{16}$. In a review of 50 cases of pulmonary hydatidosis, Balikian and Mudarris reported $60 \%$ mild hemoptysis, $20 \%$ expectoration of membranes, and $10 \%$ macroscopically visible hooks ${ }^{17}$. Other patients evolve with abdominal pain, diarrhea, and vomiting in addition to hepatitis due to cyst rupture.

Multiple pulmonary nodules resemble malignant lesions as they usually lack a capsule. Therefore, the presentation depends on the location and the involvement of adjacent structures. Chest radiography plays an important role in the diagnosis. Although most of the time, the findings are incidental and not very specific. 


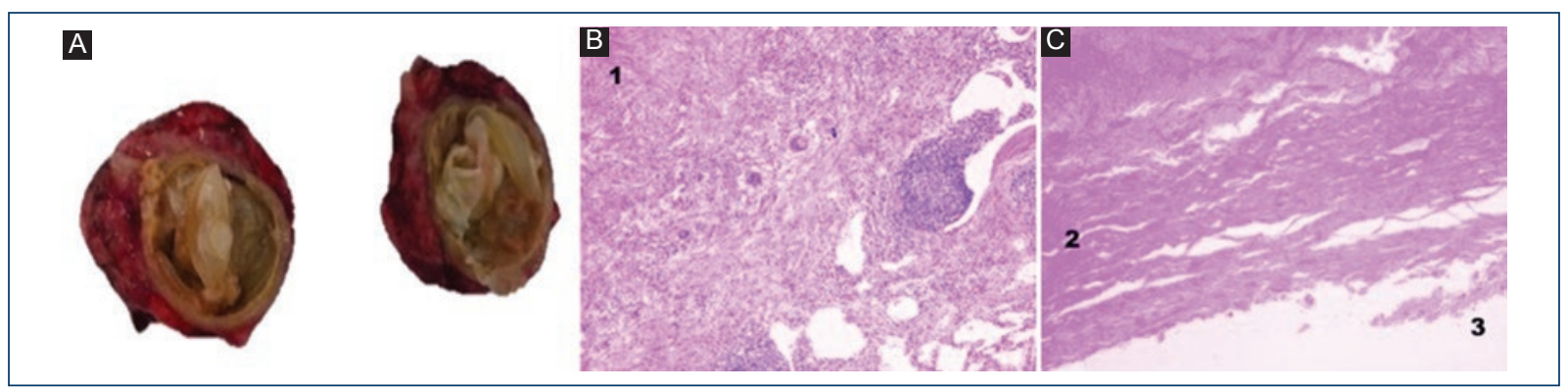

Figure 3. A: Macroscopic view of the interior of the cyst, a white-yellow, smooth and shiny coating surface is observed, delimited by a pseudocapsule of fibrous material; in cuts dyed with H-E; B: Adventitia or pericyst layer, constituted by chronic inflammatory infiltrate with formation of secondary lymphoid follicles, fibrosis, and multinuclear giant cells of foreign body type (\# 1); C: Outer layer or eosinophilia laminated acellular wall (\# 2) and no proto-schisis or escolices were found in the inner or germinative layer (\# 3).

Oval images of dentate contour and multiple notches can be observed and even in rare occasions presence of air bronchogram ${ }^{18}$. Cysts are classified as simple (preserved wall) and complicated (broken wall). The latter usually presents a sterile pleural effusion with abundant scolex to the microscopic study ${ }^{3}$. The number of cysts depends on the number of eggs leaked into the pulmonary circulation. The majority $(60-90 \%)$ are solitary and their size varies between $1 \mathrm{~cm}$ and $20 \mathrm{~cm}$ in diameter. The most frequent location is on the right side $(60 \%)$ and they predominate in the lower lobe. There are some radiographic signs directly associated: sign of increasing air, sign of Cumbo or double arch (pathognomonic), sign of camalote or lily in water, and sign of the membrane, among others ${ }^{18}$. The majority of pulmonary lesions near the liver make diagnosis even more difficult, making necessary serological studies such as the Casoni reaction, which is positive in $70 \%$ of cases. Serous eosinophilia occurs in a smaller number of patients and is more evident in cyst rupture $^{19}$.

Other studies, such as liver ultrasound, should be routine in pulmonary hydatidosis because it provides valuable information. It predicts the ability to respond to medical treatment according to the imaging characteristics ${ }^{19}$. Fluoroscopy mobile lesions that change their shape with breathing movements (sign of Escudero-Nimerov) can be observed. The contrasting CT allows us to observe small cysts, its topography and involvement of other organs. On the other hand, magnetic resonance provides data such as post-operative fistulas, recurrence, and some extrahepatic infections ${ }^{18}$. Minimally invasive studies such as fibrobronchoscopy allow the direct vision of membranes and white or transparent gelatinous material at the endobronchial level ${ }^{20}$. Monotherapy with antiparasitic drugs is usually ineffective and only recommended in patients who are not candidates for surgical treatment. Treatment with surgical resection has low mortality and a lower risk of relapse during long-term follow-up $(0.53-3.3 \%)^{21,22}$. The most common complications associated with surgery are secondary to the rupture of the cyst during the intervention. There are several types of surgical approaches that depend on the size, location, and number of cysts. One of the most used techniques in the world is that of Barrett, which allows the obliteration of the residual cavity with healthy lung tissue due to the effect of lung reexpansion after a few days or months.

Pneumonectomy, lobectomy, or segmentectomy depend on the experience of the surgeon since they are also used to resolve complications such as profuse bleeding during and after the surgical event. Another technique that has shown favorable results in a limited group of patients is percutaneous drainage ${ }^{23}$. Recently published data on percutaneous therapy PAIR (for its acronym in English) which means: puncture of the cyst, aspiration of content, injection of escolicida agent ( $\mathrm{NaCl}$ to $20-30 \%$ ), and respiration (after $3 \mathrm{~min}$ of installation) present encouraging results with minimal risk of complications by anaphylaxis $(1.1 \%)^{23,24}$.

\section{Conclusions}

Pulmonary hydatidosis is a rare disease in our country. The antecedents of exposure to sheep and the classic signs in cabinet studies allow to suspect the diagnosis and rule out the invasion of other organs. Surgical resection of the pulmonary cyst is the definitive treatment with the least number of complications. 


\section{Ethical disclosures}

Protection of human and animal subjects. The authors declare that no experiments were performed on humans or animals for this study.

Confidentiality of data. The authors declare that they have followed the protocols of their work center on the publication of patient data.

Right to privacy and informed consent. The authors have obtained the written informed consent of the patients or subjects mentioned in the article. The corresponding author is in possession of this document.

\section{References}

1. Eckert J, Schantz PM, Gasser RB, Torgerson AS, Bessonov SO, Mo vsessian SO, et al. Geographic distribution and prevalence. In: Eckert J Gemmell MA, Meslin FX, Pawlowski ZS, editors. World Health Organization (WHO)/World Organization for Animal Health (Office Internationa des Epizooties) (OIE) Manual on Echinococcosis in Humans and Animals: a Public Health Problem of Global Concern. Paris: World Organisation for Animal Health; 2002. p. 101-43.

2. Craig PS, McManus DP, Lightowlers MW, Chabalgoity JA, Garcia HH Gavidia CM, et al. Prevention and control of cystic echinococcosis. Lancet Infect Dis. 2007:7:385-94.

3. Moro P, Schantz PM. Echinococcosis: a review. Int J Infect Dis 2009;13:125-33

4. McManus DP, Zhang W, Li J, Bartley PB. Echinococcosis. Lancet. 2003; 362:1295-304.

5. MorarR, Feldman C. Pulmonary echinococcosis. Eur Respir J. 2003;21:1069-77.

6. Meimarakis G, Grigolia G, Loehe F, Jauch KW, Schauer RJ. State-ofthe-art Echinococcus and Taenia: phylogenetic taxonomy of human-pathogenic tapeworms and its application to molecular diagnosis. Eur J Med Res. 2009;14:165-70.
7. Budke CM, Deplazes P, Torgerson PR. Global socioeconomic impact of cystic echinococcosis. Emerg Infect Dis. 2006;12:296-303.

8. Yalçinkaya I, Er M, Ozbay B, Uğraş S. Surgical treatment of hydatid cyst of the lung: review of 30 cases. Eur Respir J. 1999;13:441-4.

9. Doğan R, Yüksel M, Cetin G, Süzer K, Alp M, Kaya $S$, et al. Surgical treatment of hydatid cysts of the lung: report on 1055 patients. Thorax. 1989;44:192-9.

10. Vargas RI, Martínez MJ, Jaramillo AC. Caracterización de la hidatidosis porcina en el rastro frigorífico los reyes la paz, estado de México, México. Vet Mexico. 1995;26:365-8.

11. Martínez MJ, Zúñiga Al, Jaramillo AC, Cárdenas LJ, Navarro FR. Caracterización epidemiológica de la equinococosis/hidatidosis en Zacatecas, México. Vet Mexico. 1994;25:231-7.

12. Palafox D, Palafox J, Tello B. Hidatidosis pulmonar. Reporte de dos casos clínicos. Rev Inst Nac Enferm Respir. 2009;22:32-6.

13. Bekçi TT. Diagnosis and treatment of human hydatid disease. Eur J Gen Med. 2012:9:15-20.

14. Sharma N, Xess D. Expectoration of a hydatid cyst. CMAJ. 2009;180:1227.

15. Jerray M, Benzarti M, Garrouche A, Klabi N, Hayouni A. Hydatid disease of the lungs. Study of 386 cases. Am Rev Respir Dis. 1992:146:185-9.

16. Santivanez S, Garcia HH. Pulmonary cystic echinococcosis. Curr Opin Pulm Med. 2010;16:257-61

17. Balikian JP, Mudarris FF. Hydatid disease of the lungs. A roentgenologic study of 50 cases. Am J Roentgenol Radium Ther Nucl Med. 1974; 122:692-707.

18. Garg MK, Sharma M, Gulati A, Gorsi U, Aggarwal AN, Agarwal R, et al. maging in pulmonary hydatid cysts. World J Radiol. 2016;8:581-7.

19. Brunetti E, White AC Jr. Cestode infestations: hydatid disease and cysticercosis. Infect Dis Clin North Am. 2012;26:421-35

20. Madan K, Singh N. Bronchoscopic diagnosis of pulmonary hydatid cyst. CMAJ. 2012;184:E158.

21. Wu MB, Zhang LW, Zhu H, Qian ZX. Surgical treatment for thoracic hydatidosis: review of 1230 cases. Chin Med J (Engl). 2005;118:1665-7.

22. Brunetti E, Kern P, Vuitton DA, Writing Panel for the WHO-IWGE. Expert consensus for the diagnosis and treatment of cystic and alveolar echinococcosis in humans. Acta Trop. 2010;114:1-16.

23. Halezeroglu S, Okur E, Tanyü MO. Surgical management for hydatid disease. Thorac Surg Clin. 2012;22:375-85.

24. Neumayr A, Troia G, de Bernardis C, Tamarozzi F, Goblirsch S, Piccoli L, et al. Justified concern or exaggerated fear: the risk of anaphylaxis in percutaneous treatment of cystic echinococcosis a systematic literature review. PLoS Negl Trop Dis. 2011;5:e1154. 